\title{
The Complexity of the Homeopathic Healing Response Part 2: The Role of the Homeopathic Simillimum as a Complex System in Initiating Recovery from Disease
}

\author{
Iris R. Bell ${ }^{1}$ \\ ${ }^{1}$ Department of Family and Community Medicine, The University of \\ Arizona College of Medicine, Tucson, Arizona, United States \\ Homeopathy 2020;109:51-64.
}

Address for correspondence Iris Bell, MD, PhD, 10645 North Oracle Road, Suite 121-126, Tucson, AZ 85737, United States (e-mail: ibell@email.arizona.edu).

\begin{abstract}
Keywords

- homeopathy

- complex systems

- nanostructure

- protein corona

- biological identity
\end{abstract}

Background Evidence indicates that homeopathic medicines are complex self-organizing nano-scale systems that generate unique low-intensity electromagnetic signals and/or quantum coherence domains. In Part 1, we reviewed relevant concepts from complex adaptive systems science on living systems for the nature of homeopathic healing.

Aim In Part 2, we discuss the complex-system nature of homeopathic medicines. The aim is to relate the evidence on the nature and properties of homeopathic medicines to the complex systems model for homeopathic healing.

Methods and Results The work is a narrative review, with complexity model development for the nature of homeopathic medicines. Studies suggest that homeopathic manufacturing generates nano-structures of source material, silica and silicon quantum dots if succussed in glassware or including botanical source materials; or carbon quantum dots if succussed in plastic or including any organic source materials, as well as solute-induced water nano-structures carrying medicine-specific information. On contact with physiological fluids (e.g., blood plasma), there is evidence that nanostructures additionally adsorb individualized patterns of the recipient's own proteins on to their surfaces to create a unique protein corona coat (shell). Thus, the simillimum may generate a personalized biological identity upon administration. Consequently, a medicine can serve as an individually salient, self-similar information carrier, whose protein corona constituent pattern reflects the individual's current internal state of health/disease. Homeopathic medicine complexity emerges from interactions of the component parts from source, silica from glassware or carbon from plastic containers, solvents (lactose, water, ethanol), adsorbed biomolecule layers from plant or animal sources, and adsorbed biomolecules of the recipient. Low doses of these complex medicines can act as biological signaling agents to initiate hormesis via a network-wide pattern of adaptive responses by the recipient complex adaptive system, rather than as conventional pharmaceutical drugs. Biological mediators of adaptive responses include inter-connected network elements of the cell danger/damage defense system: for example, gene expression, reactive oxygen species, heat shock proteins, cytokines, macrophages, T-cells, and associated brain-immune system mediator pathways.

Conclusions Every homeopathic medicine is a complex nano-scale system involving multiple inter-connected, interacting components, and emergent properties. received

April 16, 2019

accepted after revision

June 27, 2019

published online

November 30, 2019
Copyright $\odot 2020$ The Faculty of Homeopathy
DOI https://doi.org/ 10.1055/s-0039-1694999. ISSN 1475-4916. 
Simillimum individualization derives from formation of a unique personalized protein corona shell adsorbed to the reactive surface of the homeopathic nano-structures on contact with the recipient's body fluids. Low doses of such complex nano-structures initiate the adaptive processes of hormesis to mobilize endogenous healing of a disease state. The capacity for self-organization and self-similarity in complex systems is the key to future research on the nature of homeopathic medicines and systemic healing during individualized homeopathic treatment.

\section{Introduction}

This two-part paper focuses on the integrative model for the complex, self-organizing nature of both (a) recipient living systems ${ }^{1-4}$ and (b) homeopathic medicines ${ }^{5-10}$ as the basis for homeopathic healing. In Part 1 , we covered the basics of complex systems science to frame understanding of health and disease. Living systems are inherently complex adaptive systems (CAS). In Part 2, we synthesize and integrate thinking from a growing body of research on the nature of homeopathic medicines with evidence from modern nano-science to accommodate the data in the field. These concepts are empirically testable with appropriate study designs.

Homeopathic medicines are not conventional drugs. Conventional drugs act via biochemical, mechanistically targeted, specific direct local effects. In contrast, in this complexity model, the correct homeopathic medicine serves as a low-dose stimulus or individualized signal for inducing patterns of functional adaptive changes globally and locally in the body. The homeopathic signal captures and conveys a low or weak "dose" of the salient complex disease frequency information to the body, thereby setting in motion personalized hormetic (biphasic, non-linear) adaptive multi-system responses to reverse the disease. ${ }^{11}$

In this proposed model, the homeopathic potency signal derives from the manufacturing process. The form of the "signal" may include multi-component core-shell nanostructures from (a) source, (b) doped silicon dots from glass or (c) carbon dots from polymer plastic containers or organic manufacturing materials (lactose, ethanol, plant or animal medicine source materials) during succussions, (d) soluteand electromagnetically induced self-organized water nanostructures, and (e) surface-adsorbed biomolecules of the recipient patient upon administration. For mineral or mineral salt homeopathic medicine sources, the source materials may serve as dopants that tune the properties of whatever nano-structures form. ${ }^{12-15}$

In the present model, electromagnetic and/or optical (photon-based) information, including quantum mechanical, arises from the manufacturing procedures. ${ }^{16}$ There is nano-science evidence that the body would recognize the personal salience of the homeopathic potency signal to its current disease state because of the personalized protein corona shell from the recipient individual's own biomolecules that would immediately adsorb to form a coating around the surfaces of the medicine-related nano- structures on contact with the individual's biological fluids. ${ }^{17,18}$ It is well established that the constituent proteins from the blood plasma that form the protein corona on contact with a nano-structure reflect the current disease and/or physiological state of the individual patient. ${ }^{17}$ The nano-biointerface becomes the ultimate area for treatment personalization.

\section{Homeopathic Medicines as Complex Systems}

Given the complexity model for how healing occurs (see Part 1 of this paper), what is a homeopathic medicine that can initiate such dramatic changes in the body? Converging evidence indicates that a homeopathic medicine is itself a complex nano-scale system. ${ }^{19}$ Homeopathic medicine complexity emerges from the interaction of the component parts from source, glass (silica) or plastic (carbon) containers, solvents (lactose, ethanol, water as additional surface modifiers, and as carbon sources in the case of lactose and/or ethanol as well as organic source materials) and, ultimately, the surface-adsorbed human biomolecules of the recipient at the moment of treatment dosing. At least two separate lines of research support this postulate.

First, the homeopathic potency is capable of self-organizing and inducing formation of self-similar nano-structures in surrounding water. ${ }^{5,8,20-27}$ Second, multiple studies of plants have shown that homeopathic potencies induce formation of self-organized, unique poly-crystalline structures in the exudates of treated plant seedlings versus controls. ${ }^{6,7,28,29}$ In other words, homeopathically prepared medicines may induce formation of self-similar crystalline nano-structures in water and/or in biological fluids within a living system. These medicines may induce patterns of self-similar crystalline information in their surrounding environment. $^{30}$

Traditional homeopathic manufacturing processes generate nano-scale structures that may or may not include measurable amounts of source material (with measurement limited to the practical detection limits of the instrumentation), ${ }^{31-37}$ lactose if triturated (milled) with an insoluble source material, and, if succussed in classical glassware stoppered with natural corks, silica ${ }^{38}$ and/or cork (Quercus) or other source plant bioactive coatings. ${ }^{39,40}$ In nanotechnology, silica coatings ${ }^{41,42}$ and silicon quantum dots ${ }^{43}$ are wellknown to contribute not only electronic but also biological amplification effects. ${ }^{4-52}$ Doping and/or coating core nano- 
structures with other materials alter and tune the resultant nano-structure properties. ${ }^{53-58}$

Nanoparticles are smaller than 100 nano-meters $(\mathrm{nm})$ in diameter; the smallest sized nanoparticles are called quantum dots, with a size less than $10 \mathrm{~nm}$ in diameter. Nanoparticles in general possess extremely large reactive surface areas to which other nanoparticles and materials can adsorb, as a function of their nano-scale size. Because of their extremely small sizes, quantum dots also acquire unique electromagnetic, optical, and quantum mechanical properties. ${ }^{59}$

As an aspect of manufacturing-generated nano-structures, one study in mainstream nanotechnology indicates that ultrasound agitation of a salt solution (sodium chloride, potassium iodide) creates nanoparticles of the source material and concomitantly embeds them onto glass or polymer slide surfaces in contact with the liquid. The resultant nanoparticles can then leach back into the solution over time. ${ }^{60}$ This type of phenomenon parallels what succussions might cause in any mineral salt solution. The findings further suggest the need to compare both composition and structure of nano-structures generated during Hahnemannian (different containers for every dilution-succussion step) versus Korsakovian (the same container re-used for dilution-succussion steps at higher potencies) manufacturing methods.

Furthermore, if succussed in plastic polymer containers, it is likely that the manufacturing container, along with any lactose, ethanol or other organic materials of plant or animal origin also in solution, might also contribute photo-luminescent carbon quantum nano-dots $(<10 \mathrm{~nm}$ in diameter) and other carbon-derived nano-structures. ${ }^{12,61-65}$ Carbon dots are now a major nano-component of sensitive sensors and signal amplifiers for extremely low quantities of specific physiological metabolites and biomolecules, mineral ions, herbs, vitamins, drugs, volatile organic compounds, and other agents. ${ }^{66-69}$ As a proof of principle, it is even possible to process food waste water sources per se to synthesize photo-luminescent carbon nano-dots from their organic source material. ${ }^{70,71}$

Thus, homeopathic medicines containing carbon dots might literally serve as very crude sensor-carriers for the medicine source material and its constituent information at profoundly low femtomolar ${ }^{72}$ or picogram concentrations. ${ }^{73,74}$ One research group has termed certain carbon dots as "optic noses" for detecting and amplifying the signal of small quantities of their target agent. ${ }^{68}$ Not surprisingly, carbon as an element is detectable in plant-derived homeopathically prepared medicines. ${ }^{19,34}$

Recent work by Cartwright suggests that the homeopathic medicine's signal may depend on its dipole moment properties. Dipole emissions are a capability also documented for certain carbon nano-materials such as carbon nano-dots. ${ }^{65}$ As is true for other types of nano-materials, it is possible to tune carbon nano-dot properties by doping, modifying particle surfaces with different functional groups and adsorbents and/or changing $\mathrm{pH}^{75}$ In parallel, Elia's laboratory previously demonstrated that $\mathrm{pH}$ changes induce measurable heat release and alterations in electrical conductance of homeopathically prepared medicine solutions. ${ }^{8}$

Furthermore, multiple research groups have reported evidence that homeopathic manufacturing induces persistent formation of electromagnetic signal-induced, self-organized crystalline water nano-structures, termed "dissipative structures" by Elia et al, 8,76,77 "nano-associates" by Konovalov et al, ${ }^{20,21}$ or "nano-pearls" (poly-crystals formed of many microscopic crystallites) by Meessen. ${ }^{5}$ Crystalline structures at the nano-scale (or larger) spontaneously self-organize from an interaction of their constituent parts with each other and with their environment.

A crucial characteristic of nano-structures is that their large surfaces are highly reactive and interactive with their immediate environment. ${ }^{78}$ Materials in that environment, including but not limited to other nano-structures and various molecules (e.g., organic materials from lactose, plant or animal proteins and nucleic acids, dyes and/or minerals/ions in colloidal solutions with nano-structures), will attach (adsorb) to the outer surfaces of nano-scale structures to form new layers, coatings, or shells around the nano-structure. ${ }^{78-80}$

Multiple factors, especially surface structure and surface energetics, as well as $\mathrm{pH}$ of the surrounding solution, ${ }^{81}$ modulate the emergent properties of the resultant nanostructure coating. During the agitation such as sonication, vortexing, or manual succussions of a colloidal nano-structure solution, some of those elemental constituents, for example, nitrogen or phosphorus, as well as ethanol, may also dope the particles. ${ }^{58,80,82}$ The implosion of succussion-induced nanobubbles that form around or near nanoparticles would also add heat energy and pressure effects in generating homeopathic medicine nano-structures. ${ }^{31,83-86}$ These coatings and dopants can significantly alter the physical, chemical, and biological properties of any given nano-structure. ${ }^{53}$

Some recent research indicates that the composition of nanoparticles found in homeopathic medicines may not always contain detectable amounts of the source material because of the detection limits of the available technology. ${ }^{19}$ As always, lower limits for detection ability of the measurement instruments can be a methodological factor in these types of findings.

However, apart from debate over what the composition of the nanoparticles might be, ${ }^{19}$ there is nonetheless ample convergent evidence for the presence of poly-disperse (heterogeneous sizes) nano-structures and other materials in homeopathically prepared medicines. ${ }^{32,40}$ Evidence shows that homeopathically prepared medicines, even in higher potencies diluted past Avogadro's number for bulk forms of source materials, nonetheless retain the thermoluminescence signature signal of the original source material. ${ }^{87,88}$

Sizes of homeopathic medicine nano-structures studied range from the size of quantum dots ( $<10$ nanometers) to isolated nanoparticles ( $<100 \mathrm{~nm}$ diameter) to larger aggregates measuring hundreds of $\mathrm{nm}$ in size. ${ }^{32,34-37,39,89,90}$ Data on variations in sizes and zeta potentials (surface electrical charge properties at the interface with surrounding liquids) and calorimetric $\mathrm{pH}$ effects on potentized medicines further indicate 
differences from controls, consistent with possible differences in nano-structure coatings. $8,19,38,39,76,77,90,91$

It is also important to note for any homeopathic medicine that the cumulative effect of a greater number of triturations (mechanical milling in dry lactose) or of succussions (vigorous agitation in liquid solvent) to make higher potencies affect the final, albeit heterogeneous, nanoparticle sizes. ${ }^{92}$ Such procedures likely parallel the progressive reductions in nanoparticle sizes that occur with longer periods of mechanical milling, vortexing or ultrasonication in conventional top-down nano-technology manufacturing. ${ }^{93,94}$ As a result, smaller sized nanoparticles occur in relatively greater quantities at higher versus lower potencies. $^{92}$ There is also the potential for a low dose (i.e., smaller quantity or concentration) by smaller size (e.g., homeopathic potency nano-structures) interaction in producing various biological effects. ${ }^{18,95}$

Notably, finding evidence for a given type of agent, structure, process, or signal does not preclude the concomitant existence or possible role of another one in homeopathic information capture and delivery to the organism. In physics, electrons in atoms are electromagnetic phenomena. When an electron absorbs a photon, the electron jumps to a higher energy level. During quantum confinement of atoms and their electrons near the surface of the smallest sized nano-structures, photons (light particles, optical signals) are emitted when electrons move from a higher to a lower energy state.

Past findings of electromagnetic, ${ }^{8,25,26}$ optical, ${ }^{87,88,96,97}$ or other signals ${ }^{98-100}$ emitted from homeopathic medicines do not preclude the initial generation of different types and sizes of nanoparticles during manufacturing, 19,31-37,39,89,90,101,102 including the presumptive electromagnetic signal-induced nano-structures ${ }^{8,76,77}$ and/or quantum dot sizes already observed in potentized medicines. ${ }^{32,35-37}$ Gayen et al recently demonstrated that adding homeopathic Cuprum arsenicosum 200C potency into an electroactive polymer film used in the electronic industry markedly enhanced the conductivity and dielectric constant of the film. ${ }^{103}$ Again, homeopathic medicines appear to acquire photo-electronic properties during traditional manufacturing procedures.

Nano-structures formed in the course of serial dilutions and succussions during manufacturing, even if they represent interaction of information-containing quantum coherence domains with water, ${ }^{19,27,104-106}$ would themselves be able to generate weak (low intensity) electromagnetic and optical signals. ${ }^{25,26,63,103,107}$

Homeopathic medicine nanoparticles that are as small as quantum dots $(<10 \mathrm{~nm} \text { in diameter })^{32,35-37}$ comprise small numbers of atoms with their electron clouds trapped close to the particle surface. As a result, electron movement in quantum dot-sized nanoparticles can lead to quantum confinement, quantum entanglement, and quantum coherence phenomena, as claimed by other researchers for higher homeopathic potencies. ${ }^{77,96,104,108-116}$

Indeed, some investigators have proposed that the medicine information emerges from persistent supra-molecular aggregates of water, reflective of quantum coherence domains at the nano-scale. ${ }^{10,27,105,106,117}$ The signal information derives from the original homeopathic manufacturing process of serial dilutions followed at each dilution step by multiple succussions (intense agitation or shaking of the liquid carrier, i.e., the non-linear dynamics of fluid turbulence). ${ }^{27,98-100,106}$ Of relevance, there is a separate body of evidence for the field of quantum biology, ${ }^{118-123}$ including observations that biological information transfer occurs at the nano-scale level of the organism. $^{10,23,26,108,120,121,123-131}$

Thus, there are multiple types of materials and sizes of nano-structures documented in homeopathic medicines at a wide range of potencies. Skeptics have long questioned how any homeopathic medicine could exert different effects from any other homeopathic medicine if it were composed of "just" silica nanoparticles or some other material common in homeopathic manufacturing. Variations in particle sizes, cores and surfaces, as a function of the methods and materials used during manufacturing, may provide much of the answer. Complex interactions between the surfaces of the medicine nano-structures and the recipient patient's own biological fluids-for example, plasma or serum proteins-may provide the rest of the answer. ${ }^{18}$

\section{The Role of the Nano-Biointerface in Homeopathic Potency Effects}

Moreover, during treatment, homeopathic medicine-specific information may derive from both (a) the complex electromagnetic and/or quantum properties of the medicine itself, and (b) the emergent biological disease state of the individual recipient. In the present model, it is not possible to discover the scientific basis of homeopathic individualization by studying only the medicine, in isolation from its interaction with the individual patient who needs it. The nano-biointerface plays an essential role.

That is, critics of a nano-medicine model for homeopathic medicines overlook the enormous area and reactive nature of the surfaces of nano-structures. ${ }^{78}$ Other materials in solution with the nano-materials adsorb to the surface of most nano-structures. Most nano-technology research shows that presence or absence of ethanol in solution will affect the properties of the resultant nano-structures and their surfaces. ${ }^{58,132,133}$ Smaller versus larger particle size affects the nature of the protein corona layer adsorbed onto a given particle. ${ }^{18}$ Thus, although it is possible to make seemingly "cleaner" or "simpler" potentized medicines for research study as nano-structures, the precise materials and methods during their preparation for clinical or research use will influence their ultimate properties in vitro and in vivo.

More important for homeopathic treatment, on contact with an individual's body fluids (e.g., plasma, serum, and saliva), homeopathic nano-structures, like any nano-structures, would adsorb onto their surfaces various patterns of not only other materials in solution during manufacturing, but also a complex specific pattern of endogenous proteins from the recipient organism. ${ }^{134}$ Sick organisms exhibit unique disease- and patient-specific patterns of proteins in body fluids (-Fig. 1). ${ }^{135,136}$ 


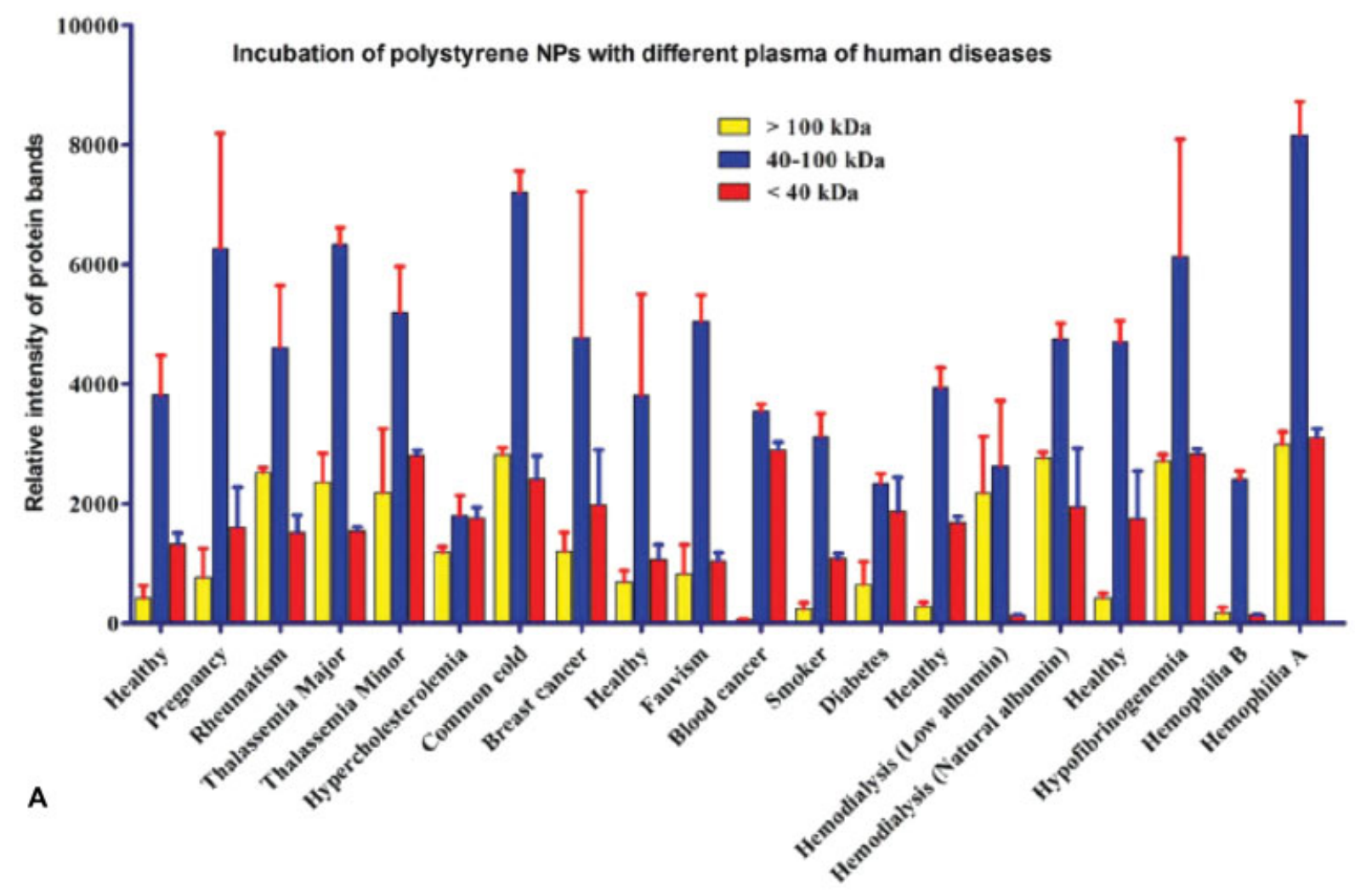

The protein composition of corona

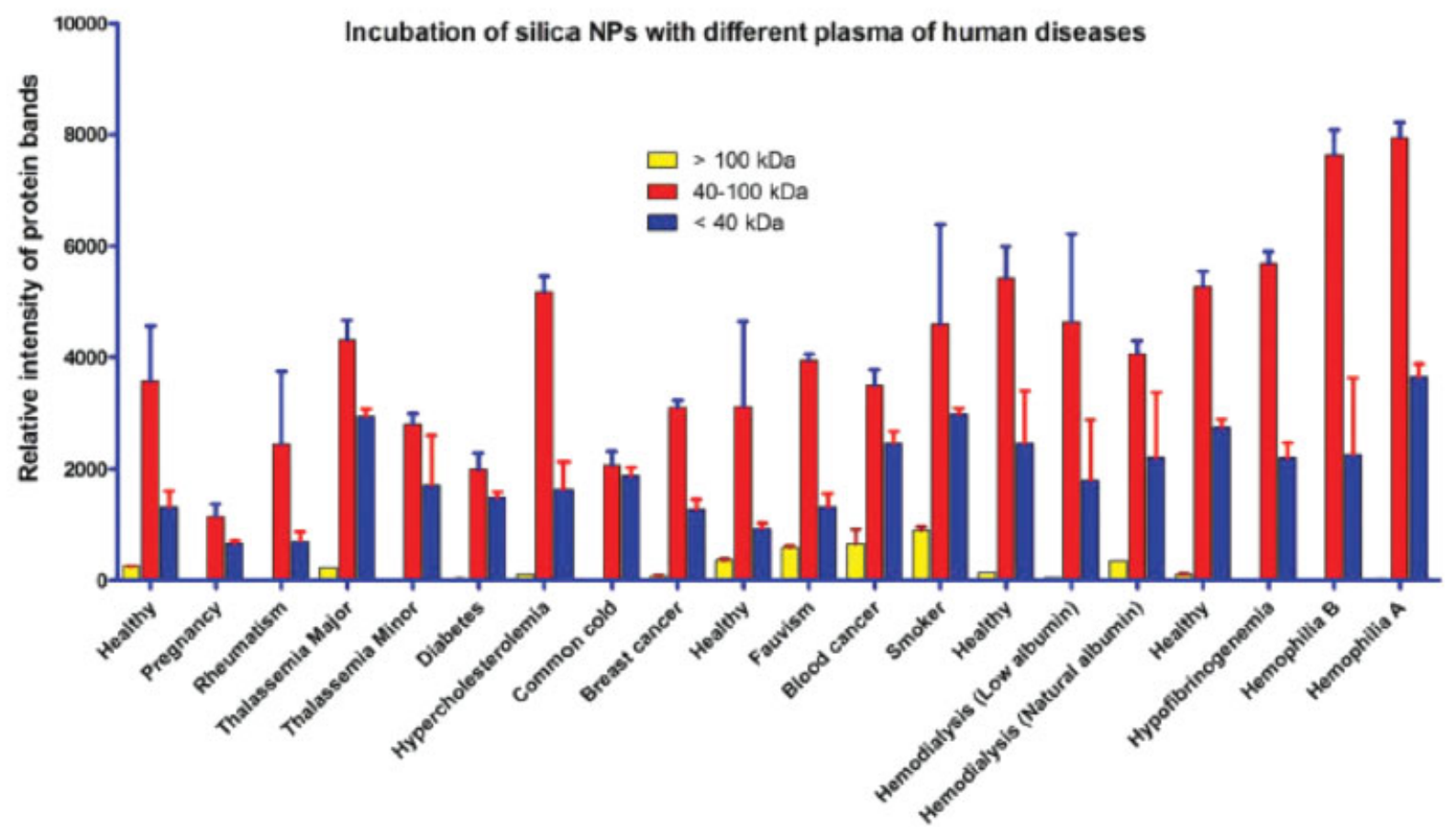

B

The protein composition of corona

Fig. 1 Histogram of the [protein corona] alterations in band intensities during incubation of (A) polystyrene and (B) silica nanoparticles with human plasma (50\%) from different patients/persons in different clinical states (healthy, pregnant, rheumatism, thalassemia major, thalassemia minor, hypercholesterolemia, common cold, breast cancer, fauvism, blood cancer, smoking, diabetes, hemodialysis (low albumin), hemodialysis (natural albumin), hyperfibrinogenemia, hemophilia B, and hemophilia A). [Data represent findings for individual patients/persons, not group averages.] Graph created from data extracted from original publication ${ }^{135}$ with permission from Royal Society of Chemistry. Note: kDA refers to kilodaltons, where a Dalton (Da) equals 1/12th the mass of a carbon atom. An average amino acid has a molecular weight of 110 to 135 Daltons. Most proteins have masses on the order of thousands of Daltons (kilodaltons, kD). 
Protein adsorption from the recipient's blood onto homeopathic nano-structures creates a protein corona layer (coating, shell) that would thereby generate a unique biological identity from that person's biological state. ${ }^{137-142}$ Notably, different allopathic diseases and clinical states (e.g., pregnancy) in conventional medicine can generate different protein corona patterns from human blood plasma on nanostructures, including both silica and polystyrene nanoparticles (-Fig. 1). ${ }^{135,136,141,143}$

Disease-related metabolomics play a role in how blood plasma proteins interact with exogenous nanoparticles. ${ }^{136}$ Smaller nanoparticle sizes, which occur at greater concentrations in higher versus lower potencies, ${ }^{36,92}$ are known to modulate the formation, composition, and properties of the protein corona that becomes the nanoparticle coat. ${ }^{17,18,134}$ In vivo, higher versus lower homeopathic potencies exert longer durations of action. ${ }^{144}$

Consequently, homeopathic nano-structures in any potency would instantly acquire a unique, individualized identity from the patient's current biological state upon administration. As a result, the simillimum would serve as a low-dose, personalized nano-encapsulation of the patient's current clinical state to signal the need for adaptive biological responses to the emergent disease process.

In this model, smaller nano-structures, including quantum dot sizes, especially in higher homeopathic potencies created by the cumulative effects of large numbers of succussions, would show not only smaller particle sizes, ${ }^{92}$ but also particle size-related variations in protein coronas formed on contact with the recipient's biological fluids (e.g., blood serum or plasma). ${ }^{134}$

In turn, the smaller nano-structures in higher potencies with their particle size-dependent unique protein coronas might initiate different biological effects than would larger nano-structures with their adsorbed protein coronas at lower homeopathic potencies (-Fig. 2). Consistent with this hypothesis, a recent plant-model study revealed that a greater number of succussions improves the effectiveness of a given medicine potency ( $45 \mathrm{x}$ ) in fostering more robust plant seedling germination resilience to a toxic stressor. ${ }^{28}$

Hormesis is a well-documented adaptive biological phenomenon in CAS involving low-dose stimulation versus highdose inhibition or toxicity of function. ${ }^{145}$ If the homeopathic medicine dose is quantitatively low, that is, in the hormetic range, ${ }^{146}$ the present model predicts that the nano-medicine information with its personalized biological identity from the protein corona would stimulate non-linear systemic changes in the opposite direction to the emergent current disease pattern for that specific patient.

The scope and specificity of the response derive from the initial conditions (i.e., dynamical biological state of the disease) of the recipient complex adaptive system. The outcome would be multiple changes in the direction of healing. For instance, acute and chronic inflammation underlie the dysfunction and pathologies across a broad spectrum of disease processes. ${ }^{147}$ However, homeopathic medicines typically mobilize multiple reversals in the biological/symptom manifestations of whatever disease or health conditions that a given individual may be experiencing. Thus, in homeopathic treatment, the quantitatively low doses of the simillimum medicine should exhibit evidence of some anti-inflammatory effects across different diseases as part of the systemic change.

In mechanistic hormesis research, Calabrese et al have documented that quantitatively low doses of many different agents/stressors-including but not limited to nano-sized particles ${ }^{145}$-initiate hormesis in part by polarizing macrophage activation patterns toward anti-inflammatory effects. ${ }^{148}$ In contrast, high or toxic doses of such agents/ stressors induce macrophage pro-inflammatory effects. ${ }^{148} \mathrm{~A}$ question that follows is whether or not homeopathic simillimum treatment modulates epigenetic expression of inflammatory biomarkers, including but not limited to favoring macrophage anti-inflammatory activation patterns.

Thus, homeopathic treatment involves treating the individual patient literally with a quantitatively low dose of his or her own current holistic biological disease state information at the nano-scale level (the homeopathic simillimum in vivo as a personalized hormetic stimulus). This first step initiates an endogenous cascade of adaptive biological signaling and hormetic systemic adaptations. The literature to date already shows that homeopathic medicines do modulate macrophage activation patterns. ${ }^{149,150}$

As a result, an area worthy of future study is the nature of the protein coronas for people with different homeopathic constitutional types or acute health conditions at baseline and over the course of treatment. This type of emergent biological identity from protein coronas potentially distinguishes homeopathic treatments using potentization-induced nano-structures from the non-individualized chemical identity of conventional drugs or even non-homeopathic nanostructures from outside the body.

In homeopathy, one investigator recently proposed using an individual's own homeopathically prepared DNA (which is inherently nano-scale), in their unique current epigenetic state of gene expression isopathically to treat miasmatic diseases. ${ }^{151}$ Separately, mainstream nano-medicine researchers are already beginning to consider the therapeutic potential of different personalized protein corona coatings on quantitatively higher dose nano-structures. ${ }^{135,136,143}$

For most clinical scenarios, however, the simillimum for the patient's current state would still be the single correctly chosen homeopathic medicine whose information resonates with and literally adsorbs onto its surface the most relevant pattern of endogenous proteins reflecting the patient's current state: that is, the biological information pattern of the recipient individual in the protein corona. ${ }^{152}$ The clinically claimed need in homeopathy for even more precise symptom pattern matching to choose the correct homeopathic medicine at higher versus lower potencies may derive in part from differences in potency-related nanoparticle sizes and consequently the resultant protein corona patterns that form. ${ }^{18}$

To a limited extent, particle sizes and zeta potential values, which assess electrical potential around nanoparticles, provide some indication of nano-structure stability 


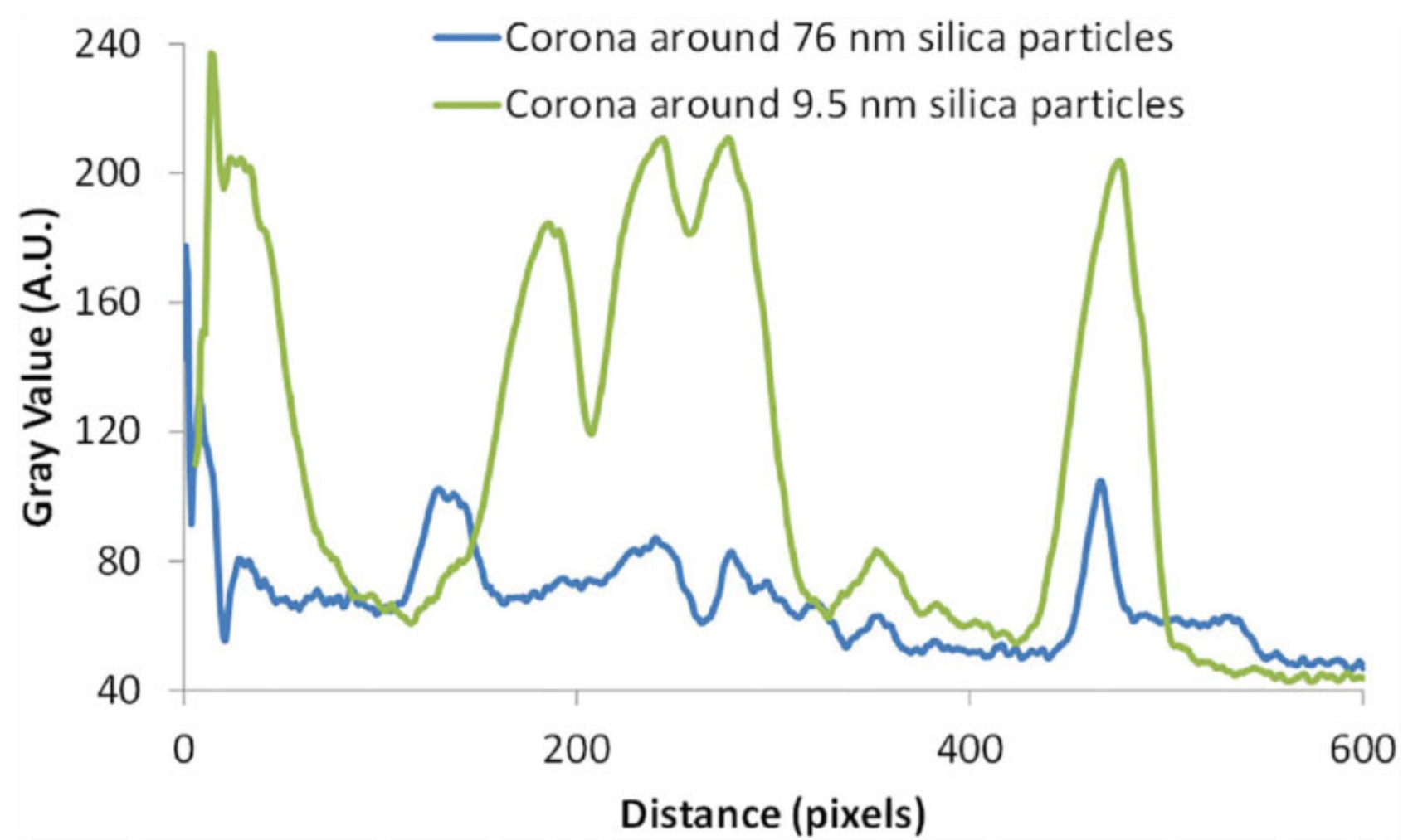

Fig. 2 Comparing the intensity of different [protein] bands for two plasma coronas from silica nanoparticles. Plasma corona from 9.5-nm silica particles in green and from 76-nm silica particles in blue. The $\mathrm{x}$-axis has been adjusted for the 10-nm silica sample since the data come from different gels. [Lundqvist et $\mathrm{al}^{18}$ : used with Creative Commons License, with attribution.] Note: Smaller versus larger particle sizes with their respective associated variants of protein corona patterns imply potential for different biological and clinical responses to higher versus lower homeopathic simillimum potencies.

and surface differences between verum homeopathic medicine and solvent controls. ${ }^{39,90}$ However, zeta potentials are not a useful measure for evaluating or differentiating the composition and properties of the protein corona. Applying newer nano-technology for examining the protein corona at the nano-biointerface, such as fluorescence correlation spectroscopy, may be necessary in studying homeopathic healing. ${ }^{17,135,136,143}$

Once the simillimum homeopathic signal interfaces and acquires its personalized biological identity from the recipient's own body, the endogenous biological signaling networks of the body can take over (see also Part 1 of this paper). Cell biology naturally involves molecular mediators of the cell danger response system as well as structures and cascades of signaling processes at the nano-sized level of scale $e^{153-157}$ (e.g., DNA double helix is $2 \mathrm{~nm}$ in diameter; cell membranes are approximately $10 \mathrm{~nm}$ thick-https://www.news-medical.net/ life-sciences/Nanoscience-Advances-in-Biology.aspx).

Nano-scale signaling for systemic change mobilizes intercellular messengers, ${ }^{158}$ including cell membrane-derived intraluminal nano-vesicles (exosomes, ranging from 30 to $100 \mathrm{~nm}$ in size), ${ }^{156}$ as well as damage/danger-associated molecular patterns (DAMPs) and associated immune cells and mediators. ${ }^{158-160}$

Consider for example the homeopathic medicine (nosode) Carcinosin, ${ }^{161,162}$ prepared from breast cancer tissue. Carcinosin potencies can induce breast cancer cell death. ${ }^{161,163}$ Most likely, Carcinosin in potency contains low quantities of cancer cell exosomes and/or genetic material information expressing the biology of cancer after undergoing the agitation of succussions.

In mainstream nano-medicine, researchers are now testing breast cancer exosomes-that is, nano-sized extracellular vesicles formed from breast cancer cells-in vaccines to prevent and/or treat breast cancer. ${ }^{157,164}$ Homeopaths have been using Carcinosin for patients with a much broader clinical picture, in addition to breast cancer per se, for a much longer period of time. Apart from malignancy, other, noncancerous, cells normally use exosomes for intercellular communication via the plasma. ${ }^{156,165}$

Environmental stressors and danger signals (from the internal and/or external environment) can arrive in the form of chemical bulk-form agents, nano-structured agents, ${ }^{158}$ electromagnetic and/or optical (photon) information, ${ }^{166,167}$ altitude, other physical factors such as cold or hot temperatures, ${ }^{168}$ or endogenous damage-related cell to cell messengers (e.g., hormones, cytokines, exosomes [nanosized vesicles carrying DNA, RNA, and proteins from their original biological cell], cell signaling pathways). ${ }^{169}$ However, it is the quantitatively low dose of the self-similar homeopathic medicine in potency that can best trigger hormesis and personalized biological healing, rather than suppress symptoms of the disease in a sick individual. ${ }^{170}$

\section{Summary and Discussion}

The fundamental description of homeopathic healing readily translates into the modern scientific terms from the field of 
complex systems or complexity. The working hypothesis here is that the correct homeopathic medicine triggers the body as a complex adaptive system (an open system far from thermodynamic equilibrium) to self-re-organize systemwide toward better health. ${ }^{146,170,171}$ The biology of the body itself occurs at the nano-scale level of organization ${ }^{172}$ using adaptive non-linear dynamical change as an essential feature in restoring and maintaining health. ${ }^{171,173,174}$ Healing is an emergent biological process.

Homeopathic medicines exhibit features of complex systems, especially self-similarity and self-organization, as shown in previously published studies of both water and plant exudates. The emergent properties of homeopathic medicines include the capacity for generating unique electromagnetic and optical emissions.

Self-organization is also a key characteristic of recipient living systems (that is, CAS). Whatever the nature of homeopathic medicines, ${ }^{175}$ the net clinical result is improved biopsychosocial resilience of the biological organism as a whole. ${ }^{145,171,176}$ The healing process engages the capacity for biological self-organization inherent in CAS to reverse disease processes. ${ }^{4,177}$ Moreover, the healing process is non-linear, in that the weak signal of the correct simillimum medicine initiates a disproportionately large response in the body.

The signal from the correct homeopathic medicine reflects resonance between the emergent information carried by the potency as a complex system ${ }^{22,178}$ and the emergent electromagnetic and biochemical properties of the recipient organism as a complex adaptive system reflected in adsorbed protein patterns from the individual's blood plasma or serum ${ }^{17}$ (- Fig. 1)..$^{22-24,178-180}$ In addition to surface electrical charge and smoothness or roughness, the size, shape, and hydrophobicity of the nano-structures affect the quantity and affinities of blood proteins that adsorb onto the nano-structure surfaces to make the personalized protein corona coats. ${ }^{181}$

The current model then suggests that quantitatively low doses of the various nano-structure-protein complexes generate the individually salient and low-intensity signal that serves as the hormetic stimulus (personalized hormetin). During homeopathic treatment of human beings or animals, the body takes over the process in two ways:

(i) adsorbing unique patterns of biomolecules (e.g., proteins) that reflect the current emergent disease state of the organism on to the homeopathic medicine nanostructure surfaces to create the protein corona coat and thus generate a personalized biological identity for the patient's body. The result would enhance specific treatment salience for the individual's current state;

(ii) modulating the biology of symptoms and healing via functional changes in neural, immune, and inflammatory pathway networks and mediators ${ }^{149,160,182-185}$ : for example, interactive components of the cell danger/ damage molecular pattern response system. ${ }^{158,170} \mathrm{~A}$ feature of the biological response is modulation of complex gene expression patterns by specific medicines. ${ }^{150,186-188}$
These adaptations are all in the service of optimizing the individual's fitness to survive in a biologically perceived environment that includes the potential disease damage or disease-encapsulated "danger" of the homeopathic medicine, as signaled by detection of the low-dose homeopathic information (that is, an individualized integrated form of the current disease state of the person).

The implication is that using the homeopathic simillimum medicine as a personalized hormetin will modulate the interrelationships and interactions of endogenous biological signaling networks to initiate disease recovery, a hypothesis supported by studies of certain homeopathic medicines in animal or cellular models for cancer. ${ }^{189-193}$

If the system is already diseased in some way, it is at or close to its physiological limits (cf. time-dependent sensitization and oscillation). ${ }^{194,195}$ The body will potentially exhibit transient aggravation up to its physiological limits and then reverse its direction of change back from disease toward a healthier degree of complexity, following the arrival of a quantitatively low-dose, hormetic salient stimulus to do so. 196,197

As a quantitatively low-dose warning signal to adapt, ${ }^{11,190}$ the homeopathic medicine does not require a conventional pharmaceutical-level dose or quantity, be it some type of nano-structure, ${ }^{19-21,31,32,34-37,39,83,84,90,107,185}$ an electromagnetic and/or optical signal that emanates from such structures, $8,25,26,76,87,97,198$ and/or some other physicalchemistry phenomenon. ${ }^{98-100}$

This present complexity-based model requires the nanobiointerface between the individual patient's current biological condition and the simillimum nano-medicine properties. The clinical state-dependent individual protein corona forms a unique biological identity for the medicine nano-structures to fulfil their simillimum role, on contact with the patient's own blood plasma, serum, and/or saliva.

Hormesis evolves as an adaptive pattern of endogenous responses to the homeopathic information/signal. It follows from the model that effective homeopathic treatment requires not only (1) quantitatively low doses of unique nano-structures salient to the current state of the recipient patient; but also (2) an interaction at the nano-biointerface between the medicine nano-structure surfaces and the patient's own blood plasma or serum proteins to form the personalized protein corona as the hormetic signal; and (3) subsequent adaptive evolution of better health via interactive self-reorganization of the organism's non-linear dynamical networks and sub-systems across multiple levels of scale (see Part 1).

Finally, research questions for testing this model include:

- Does the homeopathic simillimum medicine, but not a clinically incorrect medicine or a placebo, emit unique homeopathic signal information that attracts a highly representative, patient state-specific pattern of plasma protein adsorption on to the nano-structure surfaces?

- Does the complex medicine system, on interface with the body as a complex adaptive system, thereby create a low quantitative dose, personalized hormetic signal 
encapsulating the individual's current disease state (protein corona adsorption pattern) to initiate the adaptive changes of healing?

- Do higher versus lower homeopathic potencies of the same medicine exhibit different physico-chemical and/or biological properties at the nano-scale level of organization: for example, different nano-structure sizes and shapes, surface charges, protein corona adsorption patterns, durations of action?

- To what extent do the biological mechanisms of endogenous signal amplification processes, such as stochastic resonance, hormesis, and time-dependent sensitization (see Part 1), play a role in the nature, direction, and magnitude of clinical responses to homeopathic simillimum treatment?

- Do the biological networks involved in simillimum responses include reactive oxygen species, DAMPs, including but not limited to heat shock proteins, exosomes, and specific components of the immune system such as macrophages as part of the endogenous signaling process?

This complexity model for homeopathic medicine also requires adopting nano-materials research technologies and methods that can objectively document existence of-and manufacturing materials and methods-related variations in -the complexity of homeopathic medicine-derived signals, protein corona formation, and biological effects.

\section{Conclusions}

In conclusion, the evidence suggests that every homeopathic medicine is a complex nano-scale system involving multiple inter-connected, interacting components (coreshell nano-structures of source, silica/silicon or carbon, modified by lactose and/or ethanol-water solvent), and emergent electromagnetic, opto-electronic, quantum, and biological properties.

Homeopathic nano-structure sizes may vary as a function of trituration and subsequent succussions, surface electrical and adsorptive properties, shells formed from lactose, silica, and/or other materials in solution (e.g., made from plant source extracts, or from cork extract if containers are stoppered with natural cork), and animal source materials. The smallest nano-structures, for example, source, silicon, or carbon quantum dots, may or may not be detectable in a given study because of limitations in methodological approaches or in technological instrumentation tools (e.g., lower limits for assays of trace amounts of elements with specialized mass spectroscopy or lower limits for very small particle size detection [e.g., quantum dots] with nanoparticle tracking analysis instruments).

In this adaptive network nano-medicine model, ${ }^{146,170}$ specific biological individualization would derive from the formation of a unique personalized protein corona layer that instantly adsorbs on to the reactive surface of the homeopathic simillimum nano-structures on contact with a patient's own blood plasma, serum, or saliva. The protein components of the patient's biological fluids reflect the current biological state of the patient as reflected in the self-similar symptom pattern exhibited across the selforganized complex adaptive system of the body. Furthermore, the smaller nanoparticle sizes found at higher homeopathic potencies ${ }^{92}$ may play a role in variations in the protein corona patterns formed on contact with biological fluids and their subsequent physiological effects ${ }^{18}$ : for example, longer duration of action. ${ }^{144}$

These quantitatively low doses of such complex nanostructures in homeopathic potencies initiate the endogenous adaptive processes of hormesis and related phenomena to mobilize reversal of disease manifestations (see Part 1). The capacity for self-organization, structural and functional selfsimilarity, and emergence in complex systems, is the key to designing future research on not only the nature of homeopathic medicines, but also emergent systemic healing during individualized homeopathic treatment. The previously proposed term of "adaptive network nanomedicine" 146,170 for the present model encompasses the existing data and suggests a research path forward.

\section{Highlights}

- Evidence suggests that each homeopathic medicine is a complex multi-component, core-shell and/or doped nano-structured system ranging in sizes from 1 to $100 \mathrm{~nm}$ in diameter and exhibiting properties of selforganization, self-similarity, and emergence.

- The nano-scale components of homeopathic medicine's core and shell include source materials, silica and silicon quantum dots (if manufactured in glassware and/or containing plant-source materials), carbon nano-structures including carbon quantum dots (if manufactured in plastic containers and/or containing any organic materials from source, lactose, or ethanol), and water nano-structures.

- The homeopathic simillimum nano-structures emit unique electromagnetic and opto-electronic signals as well as exhibit quantum mechanical properties.

- On contact with a specific patient's plasma or serum, the current model proposes that the homeopathic nanostructures adsorb clinical state-specific patterns of proteins and other biomolecules on to their surfaces, thereby creating a personalized protein corona coat and biological identity reflective of the patient's current biological state (e.g., health versus specific disease or clinical state).

- Homeopathic simillimum as an individualized treatment would derive, at the nano-biointerface from the interaction of the emergent signal, properties of the correctly matched medicine and the individual patient's own unique biological state (protein corona state-specific pattern) at quantitatively low - that is, hormetic - doses. Smaller nanoparticle sizes in higher versus lower potencies may also affect the specific protein corona patterns and thus biological effects.

- Hormetic doses of the individual's encapsulated illness biology on the simillimum's nano-structure surface protein corona coat/layer would serve as adaptive triggers for homeopathic healing from disease. 
Funding

None.

\section{Conflict of Interest}

Dr. Bell is a consultant to Standard Homeopathic/Hyland's Inc., a US-based manufacturer of homeopathic medicines. The company did not provide financial support for this manuscript.

\section{References}

1 Bell IR, Baldwin CM, Schwartz GE. Translating a nonlinear systems theory model for homeopathy into empirical tests. Altern Ther Health Med 2002;8:58-66

2 Bellavite P. Complexity science and homeopathy: a synthetic overview. Homeopathy 2003;92:203-212

3 Bellavite P, Olioso D, Marzotto M, Moratti E, Conforti A. A dynamic network model of the similia principle. Complement Ther Med 2013;21:750-761

4 Camazine S, Deneubourg JL, Franks NR, Sneyd J, Theraulaz G, Bonabeau E. Self-Organization in Biological Systems. Princeton, NJ: Princeton University Press; 2003

5 Meessen A. Water memory due to chains of nano-pearls. J Mod Phys 2018;9:2657-2724

6 Baumgartner S, Doesburg P, Scherr C, Andersen JO. Development of a biocrystallisation assay for examining effects of homeopathic preparations using cress seedlings. Evid Based Complement Alternat Med 2012;2012:125945

7 Kokornaczyk MO, Baumgartner S, Betti L. Polycrystalline structures formed in evaporating droplets as a parameter to test the action of Zincum metallicum $30 \mathrm{c}$ in a wheat seed model. Homeopathy 2016;105:173-179

8 Elia V, Marrari LA, Napoli E. Aqueous nanostructures in water induced by electromagnetic fields emitted by EDS. J Therm Anal Calorim 2012;107:843-851

9 Elia V, Napoli E. Dissipative structures in extremely diluted solutions of homeopathic medicines: a molecular model based on physico-chemical and gravimetric evidences. Int J Des Nat Ecodyn 2010;5:39-48

10 Germano R. Water's quantum structures and life. Electromagn Biol Med 2015;34:133-137

11 Shahabi S, Kasariyans A, Noorbakhsh F. Like cures like: a neuroimmunological model based on electromagnetic resonance. Electromagn Biol Med 2013;32:508-526

12 Hu S, Trinchi A, Atkin P, Cole I. Tunable photoluminescence across the entire visible spectrum from carbon dots excited by white light. Angew Chem Int Ed Engl 2015;54:2970-2974

13 Sagadevan S, Chowdhury ZZ, Johan MRB, et al. Cu-doped $\mathrm{SnO}_{2}$ nanoparticles: synthesis and properties. J Nanosci Nanotechnol 2019;19:7139-7148

14 Pradeev Raj K, Sadaiyandi K, Kennedy A, et al. Influence of Mg doping on $\mathrm{ZnO}$ nanoparticles for enhanced photocatalytic evaluation and antibacterial analysis. Nanoscale Res Lett 2018;13:229

15 Chen J, Liu J, Li J, Xu L, Qiao Y. One-pot synthesis of nitrogen and sulfur co-doped carbon dots and its application for sensor and multicolor cellular imaging. J Colloid Interface Sci 2017; 485:167-174

16 Guedes JRP, Bonamin LV, Capelozzi VL. Water-related mechanisms proposed for storing and transmitting homeopathic information: putative links with biological responses. Homeopathy 2018;107:172-180

17 Corbo C, Molinaro R, Tabatabaei M, Farokhzad OC, Mahmoudi M. Personalized protein corona on nanoparticles and its clinical implications. Biomater Sci 2017;5:378-387

18 Lundqvist M, Augustsson C, Lilja M, et al. The nanoparticle protein corona formed in human blood or human blood fractions. PLoS One 2017;12:e0175871
19 Van Wassenhoven M, Goyens M, Capieaux E, Devos P, Dorfman P. Nanoparticle characterisation of traditional homeopathically manufactured cuprum metallicum and gelsemium sempervirens medicines and controls. Homeopathy 2018;107:244-263

20 Konovalov A, Ryzhkina I, Maltzeva E, et al. Nanoassociate formation in highly diluted water solutions of potassium phenosan with and without permalloy shielding. Electromagn Biol Med 2015;34:141-146

21 Konovalov AI, Ryzhkina IS. Highly diluted aqueous solutions: formation of nano-sized molecular assemblies (nanoassociates). Geochem Int 2014;52:1207-1226

22 Foletti A, Grimaldi S, Lisi A, Ledda M, Liboff AR. Bioelectromagnetic medicine: the role of resonance signaling. Electromagn Biol Med 2013;32:484-499

23 Foletti A, Ledda M, Grimaldi S, et al. The trail from quantum electro dynamics to informative medicine. Electromagn Biol Med 2015;34:147-150

24 Foletti A, Ledda M, Lolli MG, Grimaldi S, Lisi A. Electromagnetic information transfer through aqueous system. Electromagn Biol Med 2017;36:289-294

25 Montagnier L, Aïssa J, Ferris S, Montagnier JL, Lavallée C. Electromagnetic signals are produced by aqueous nanostructures derived from bacterial DNA sequences. Interdiscip Sci 2009; $1: 81-90$

26 Montagnier L, Del Giudice E, Aïssa J, et al. Transduction of DNA information through water and electromagnetic waves. Electromagn Biol Med 2015;34:106-112

27 Czerlinski G, Ypma T. Domains of water molecules provide mechanisms of potentization in homeopathy. Water Journal 2010;2:1-13

28 Betti L, Trebbi G, Kokornaczyk MO, et al. Number of succussion strokes affects effectiveness of ultra-high-diluted arsenic on in vitro wheat germination and polycrystalline structures obtained by droplet evaporation method. Homeopathy 2017; 106:47-54

29 Kokornaczyk MO, Trebbi G, Dinelli G, et al. Droplet evaporation method as a new potential approach for highlighting the effectiveness of ultra high dilutions. Complement Ther Med 2014; 22:333-340

30 Kokornaczyk MO, Scherr C, Bodrova NB, Baumgartner S. Phasetransition-induced pattern formation applied to basic research on homeopathy: a systematic review. Homeopathy 2018;107:181-188

31 Chikramane PS, Kalita D, Suresh AK, Kane SG, Bellare JR. Why extreme dilutions reach non-zero asymptotes: a nanoparticulate hypothesis based on froth flotation. Langmuir 2012;28:15864-15875

32 Chikramane PS, Suresh AK, Bellare JR, Kane SG. Extreme homeopathic dilutions retain starting materials: a nanoparticulate perspective. Homeopathy 2010;99:231-242

33 Upadhyay RP, Nayak C. Homeopathy emerging as nanomedicine. Int J High Dilution Res 2011;10:299-310

34 Rajendran ES. Field emission scanning electron microscopic (FESEM) and energy dispersive spectroscopic (EDS) studies of centesimal scale potencies of the homeopathic drug Lycopodium clavatum. Am J Homeopath Med 2015;108:9-18

35 Rajendran ES. An evaluation of Avogadro's number in the light of HRTEM and EDS studies of high dilutions of Ferrum metallicum 6, 30, 200, 1M, 10M and 50 Mc. Int J High Dilution Res 2015;14:3-9

36 Rajendran ES. Homeopathy a material science: nanoparticle characterization of aurum metallicum 6C, 30C, 200C, 1000C, 10000C, 50000C and 100000C. Int J Curr Res 2017;9:48923-48927

37 Rajendran ES. Homeopathy as nanomedicine - identification and characterization of NPs in hypericum perforatum 6C, 30C, 200C, 1M, 10M, 50M, and CM. Int J Development Res 2017;7:12425-12431

38 Temgire MK, Suresh AK, Kane SG, Bellare JR. Establishing the interfacial nano-structure and elemental composition of homeopathic medicines based on inorganic salts: a scientific approach. Homeopathy 2016;105:160-172 
39 Bell IR, Muralidharan S, Schwartz GE. Nanoparticle characterization of traditional homeopathically-manufactured Gelsemium sempervirens medicines and placebo controls. J Nanomedine Biotherapeutic Discov 2015;6:1000136

40 Das S, Das J, Samadder A, Bhattacharyya SS, Das D, KhudaBukhsh AR. Biosynthesized silver nanoparticles by ethanolic extracts of Phytolacca decandra, Gelsemium sempervirens, Hydrastis canadensis and Thuja occidentalis induce differential cytotoxicity through G2/M arrest in A375 cells. Colloids Surf B Biointerfaces 2013;101:325-336

41 Chaikin Y, Kedem O, Raz J, Vaskevich A, Rubinstein I. Stabilization of metal nanoparticle films on glass surfaces using ultrathin silica coating. Anal Chem 2013;85:10022-10027

42 Zhai C, Lu Q, Chen X, Peng Y, Chen L, Du S. Molecularly imprinted layer-coated silica nanoparticles toward highly selective separation of active diosgenin from Dioscorea nipponica Makino. J Chromatogr A 2009;1216:2254-2262

43 Spruijtenburg PC, Amitonov SV, Wiel WGV, Zwanenburg FA. A fabrication guide for planar silicon quantum dot heterostructures. Nanotechnology 2018;29:143001

44 Brandenberger C, Rowley NL, Jackson-Humbles DN, et al. Engineered silica nanoparticles act as adjuvants to enhance allergic airway disease in mice. Part Fibre Toxicol 2013;10:26

45 Demento SL, Eisenbarth SC, Foellmer HG, et al. Inflammasomeactivating nanoparticles as modular systems for optimizing vaccine efficacy. Vaccine 2009;27:3013-3021

46 Mahony D, Cavallaro AS, Stahr F, Mahony TJ, Qiao SZ, Mitter N. Mesoporous silica nanoparticles act as a self-adjuvant for ovalbumin model antigen in mice. Small 2013;9:3138-3146

47 Wang T, Jiang H, Zhao Q, Wang S, Zou M, Cheng G. Enhanced mucosal and systemic immune responses obtained by porous silica nanoparticles used as an oral vaccine adjuvant: effect of silica architecture on immunological properties. Int J Pharm 2012;436:351-358

48 Chinnathambi S, Chen S, Ganesan S, Hanagata N. Silicon quantum dots for biological applications. Adv Healthc Mater 2014; 3:10-29

49 Clark RJ, Dang MK, Veinot JG. Exploration of organic acid chain length on water-soluble silicon quantum dot surfaces. Langmuir 2010;26:15657-15664

50 Das D, Samanta A. Photoluminescent silicon quantum dots in core/shell configuration: synthesis by low temperature and spontaneous plasma processing. Nanotechnology 2011; 22:055601

51 Zhang Y, Han X, Zhang J, et al. Photoluminescence of silicon quantum dots in nanospheres. Nanoscale 2012;4:7760-7765

52 Zhou T, Anderson RT, Li H, et al. Bandgap tuning of silicon quantum dots by surface functionalization with conjugated organic groups. Nano Lett 2015;15:3657-3663

53 Cao G, Wang Y. Nanostructures and Nanomaterials: Synthesis, Properties, and Applications. 2nd ed. New Jersey: World Scientific; 2011

54 Rahman K, Khan SU, Fahad S, et al. Nano-biotechnology: a new approach to treat and prevent malaria. Int J Nanomedicine 2019; 14:1401-1410

55 Sur I, Altunbek M, Kahraman M, Culha M. The influence of the surface chemistry of silver nanoparticles on cell death. Nanotechnology 2012;23:375102

56 Sur I, Cam D, Kahraman M, Baysal A, Culha M. Interaction of multi-functional silver nanoparticles with living cells. Nanotechnology 2010;21:175104

57 Oliva-Chatelain BL, Ticich TM, Barron AR. Doping silicon nanocrystals and quantum dots. Nanoscale 2016;8:1733-1745

58 Yang Y, Yang AL, Yang RQ Yuan GJ, Shi YL. Investigation of the enhancement fluorescence of ethanol doped SiO2 nanoparticles. J Nanosci Nanotechnol 2011;11:9717-9720

59 Malfatti L, Innocenzi P. Sol-gel chemistry for carbon dots. Chem Rec 2018;18:1192-1202
60 Kiel S, Grinberg O, Perkas N, Charmet J, Kepner H, Gedanken A. Forming nanoparticles of water-soluble ionic molecules and embedding them into polymer and glass substrates. Beilstein J Nanotechnol 2012;3:267-276

61 Chan KM, Xu W, Kwon H, Kietrys AM, Kool ET. Luminescent carbon dot mimics assembled on DNA. J Am Chem Soc 2017; 139:13147-13155

62 Loi E, Ng RW, Chang MM, Fong JF, Ng YH, Ng SM. One-pot synthesis of carbon dots using two different acids and their respective unique photoluminescence property. Luminescence 2017;32:114-118

63 Park SY, Lee CY, An HR, et al. Advanced carbon dots via plasmainduced surface functionalization for fluorescent and bio-medical applications. Nanoscale 2017;9:9210-9217

64 Papaioannou N, Marinovic A, Yoshizawa N, et al. Structure and solvents effects on the optical properties of sugar-derived carbon nanodots. Sci Rep 2018;8:6559-6559

65 Ghosh S, Chizhik AM, Karedla N, et al. Photoluminescence of carbon nanodots: dipole emission centers and electron-phonon coupling. Nano Lett 2014;14:5656-5661

66 He JH, Cheng YY, Yang T, Zou HY, Huang CZ. Functional preserving carbon dots-based fluorescent probe for mercury (II) ions sensing in herbal medicines via coordination and electron transfer. Anal Chim Acta 2018;1035:203-210

67 Li Z, Zhang J, Li Y, et al. Carbon dots based photoelectrochemical sensors for ultrasensitive detection of glutathione and its applications in probing of myocardial infarction. Biosens Bioelectron 2018;99:251-258

68 Zheng M, Li Y, Zhang Y, Xie Z. Solvatochromic fluorescent carbon dots as optic noses for sensing volatile organic compounds. RSC Advances 2016;6:83501-83504

69 Chan KK, Yap SHK, Yong KT. Biogreen synthesis of carbon dots for biotechnology and nanomedicine applications. Nano-Micro Lett 2018;10:72

70 Park SY, Lee HU, Park ES, et al. Photoluminescent green carbon nanodots from food-waste-derived sources: large-scale synthesis, properties, and biomedical applications. ACS Appl Mater Interfaces 2014;6:3365-3370

71 Pramanik A, Biswas S, Kumbhakar P. Solvatochromism in highly luminescent environmental friendly carbon quantum dots for sensing applications: conversion of bio-waste into bio-asset. Spectrochim Acta A Mol Biomol Spectrosc 2018;191:498-512

72 Qaddare SH, Salimi A. Amplified fluorescent sensing of DNA using luminescent carbon dots and AuNPs/GO as a sensing platform: a novel coupling of FRET and DNA hybridization for homogeneous HIV-1 gene detection at femtomolar level. Biosens Bioelectron 2017;89:773-780

73 Teixeira S, Conlan RS, Guy OJ, Sales MGF. Label-free human chorionic gonadotropin detection at picogram levels using oriented antibodies bound to graphene screen-printed electrodes. J Mater Chem B Mater Biol Med 2014;2:1852-1865

74 Rasheed PA, Sandhyarani N. Carbon nanostructures as immobilization platform for DNA: a review on current progress in electrochemical DNA sensors. Biosens Bioelectron 2017; 97:226-237

75 Dimos K. Carbon quantum dots: surface passivation and functionalization. Curr Org Chem 2016;20:682-695

76 Elia V, Ausanio G, Gentile F, Germano R, Napoli E, Niccoli M. Experimental evidence of stable water nanostructures in extremely dilute solutions, at standard pressure and temperature. Homeopathy 2014;103:44-50

77 Elia V, Germano R, Napoli E. Permanent dissipative structures in water: the matrix of life? Experimental evidences and their quantum origin. Curr Top Med Chem 2015;15:559-571

78 Mudunkotuwa IA, Grassian VH. The devil is in the details (or the surface): impact of surface structure and surface energetics on understanding the behavior of nanomaterials in the environment. J Environ Monit 2011;13:1135-1144 
79 Shang L, Nienhaus GU. In situ characterization of protein adsorption onto nanoparticles by fluorescence correlation spectroscopy. Acc Chem Res 2017;50:387-395

80 Poshteh Shirani M, Rezaei B, Ensafi AA. A novel optical sensor based on carbon dots embedded molecularly imprinted silica for selective acetamiprid detection. Spectrochim Acta A Mol Biomol Spectrosc 2019;210:36-43

81 Givens BE, Xu Z, Fiegel J, Grassian VH. Bovine serum albumin adsorption on $\mathrm{SiO}_{2}$ and $\mathrm{TiO}_{2}$ nanoparticle surfaces at circumneutral and acidic $\mathrm{pH}$ : a tale of two nano-bio surface interactions. J Colloid Interface Sci 2017;493:334-341

82 Mikhaylov AN, Tetelbaum DI, Burdov VA, et al. Effect of ion doping with donor and acceptor impurities on intensity and lifetime of photoluminescence from $\mathrm{SiO} 2$ films with silicon quantum dots. J Nanosci Nanotechnol 2008;8:780-788

83 Demangeat JL. Nanosized solvent superstructures in ultramolecular aqueous dilutions: twenty years' research using water proton NMR relaxation. Homeopathy 2013;102:87-105

84 Demangeat JL. Gas nanobubbles and aqueous nanostructures: the crucial role of dynamization. Homeopathy 2015;104: 101-115

85 Roy R, Tiller W, Bell IR, Hoover MR. The structure of liquid water: novel insights from materials research and potential relevance to homeopathy. Mater Res Innov 2005;9:577-608

86 Rao ML, Roy R, Bell IR, Hoover R. The defining role of structure (including epitaxy) in the plausibility of homeopathy. Homeopathy $2007 ; 96: 175-182$

87 Rey L. Thermoluminescence of ultra-high dilutions of lithium chloride and sodium chloride. Physica A 2003;323:67-74

88 Rey L. Can low-temperature thermoluminescence cast light on the nature of ultra-high dilutions? Homeopathy 2007;96: $170-174$

89 Stovbun SV, Kiselev AV, Zanin AM, et al. Effects of physicochemical forms of phenazepam and Panavir on their action at ultra-low doses. Bull Exp Biol Med 2012;153:455-458

90 Bell IR, Muralidharan S, Schwartz GE. Nanoparticle characterization of traditional homeopathically-manufactured silver (Argentum Metallicum) medicines and placebo controls. J Nanomed Nanotechnol 2015;6:311

91 Elia V, Napoli E, Germano R. The 'Memory of Water': an almost deciphered enigma. Dissipative structures in extremely dilute aqueous solutions. Homeopathy 2007;96:163-169

92 Kar S, Bandyopadhyaya P, Chakraborty S, et al. Derivation of an empirical relation between the size of the nanoparticle and the potency of homeopathic medicines. Int J High Dilution Res 2015; $14: 2-7$

93 Arole VM, Munde SV. Fabrication of nanomaterials by top-down and bottom-up approaches - an overview. J Adv Applied Sciences Technology Material Science 2014;1:89-93

94 Sengel C, Hasçiçek C, Gönül N. Design of vitamin E d- $\alpha$-tocopheryl polyethylene glycol 1000 succinate-emulsified poly (D, Llactide-co-glycolide) nanoparticles: influence of duration of ultrasonication energy. J Young Pharm 2011;3:171-175

95 Alessandrini F, Vennemann A, Gschwendtner S, et al. Pro-inflammatory versus immunomodulatory effects of silver nanoparticles in the lung: the critical role of dose, size and surface modification. Nanomaterials (Basel) 2017;7:300

96 Lenger K, Bajpai RP, Drexel M. Delayed luminescence of high homeopathic potencies on sugar globuli. Homeopathy 2008; 97:134-140

97 Lenger K, Bajpai RP, Spielmann M. Identification of unknown homeopathic remedies by delayed luminescence. Cell Biochem Biophys 2014;68:321-334

98 Cartwright SJ. Solvatochromic dyes detect the presence of homeopathic potencies. Homeopathy 2016;105:55-65

99 Cartwright SJ. Interaction of homeopathic potencies with the water soluble solvatochromic dye bis-dimethylaminofuchsone. Part 1: pH studies. Homeopathy 2017;106:37-46
100 Cartwright SJ. Degree of response to homeopathic potencies correlates with dipole moment size in molecular detectors: implications for understanding the fundamental nature of serially diluted and succussed solutions. Homeopathy 2018;107:19-31

101 Upadhyay RP. The possible mechanism of memory through nanoparticles and exclusion zones. Water 2017;7:158-176

102 Perry CC, Keeling-Tucker T. Crystalline silica prepared at room temperature from aqueous solution in the presence of intrasilica bioextracts. Chem Commun (Camb) 1998;1998:2587-2588

103 Gayen A, Mondal D, Bandyopadhyay P, et al. Effect of homeopathic dilutions of cuprum arsenicosum on the electrical properties of poly(vinylidene fluoride-co-hexafluoropropylene). Homeopathy 2018;107:130-136

104 Tournier A. Quantum coherence domains and nanoparticles one and the same thing? Homeopathy 2014;103:79-80

105 Czerlinski G, Ypma T. Homeopathic potentization based on nanoscale domains. J Altern Complement Med 2011;17: 1165-1173

106 Czerlinski G, Ypma T. The targets of information-carrying nanodomains. J Nanosci Nanotechnol 2012;12:2239-2247

107 Mahata CR. Dielectric dispersion studies of some potentised homeopathic medicines reveal structured vehicle. Homeopathy 2013;102:262-267

108 Foletti A, Lisi A, Ledda M, de Carlo F, Grimaldi S. Cellular ELF signals as a possible tool in informative medicine. Electromagn Biol Med 2009;28:71-79

109 Fisher P. Local, entangled or both? Homeopathy 2013;102:85-86

110 Manzalini A, Galeazzi B. Explaining homeopathy with quantum electrodynamics. Homeopathy 2019; Epub ahead of print

111 Molski M. Quasi-quantum phenomena: the key to understanding homeopathy. Homeopathy 2010;99:104-112

112 Thieves K, Gleiss A, Kratky KW, Frass M. First evidence of Beauvais' hypothesis in a plant model. Homeopathy 2016;105:270-279

113 Walach H. Entanglement model of homeopathy as an example of generalized entanglement predicted by weak quantum theory. Forsch Komplementarmed Klass Naturheilkd 2003;10:192-200

114 Weingärtner O. Homeopathy and quantum field theory. Forsch Komplement Med 2006;13:140

115 Beauvais F. A quantum-like model of homeopathy clinical trials: importance of in situ randomization and unblinding. Homeopathy 2013;102:106-113

116 Van Wassenhoven M, Goyens M, Henry M, Capieaux E, Devos P. Nuclear Magnetic Resonance characterization of traditional homeopathically manufactured copper (Cuprum metallicum) and plant (Gelsemium sempervirens) medicines and controls. Homeopathy 2017;106:223-239

117 Czerlinski G, Ypma T. Stabilization of aqueous electromeric nano-domains. J Comput Theor Nanosci 2011;8:1400-1408

118 Tofani S. Electromagnetic energy as a bridge between atomic and cellular levels in the genetics approach to cancer treatment. Curr Top Med Chem 2015;15:572-578

119 McFadden JJ, Al-Khalili J. Life on the Edge: The Coming of Age of Quantum Biology. New York: Crown Publishers; 2014

120 Streltsov A, Singh U, Dhar HS, Bera MN, Adesso G. Measuring quantum coherence with entanglement. Phys Rev Lett 2015; 115:020403

121 Tarlacı S, Pregnolato M. Quantum neurophysics: from non-living matter to quantum neurobiology and psychopathology. Int J Psychophysiol 2016;103:161-173

122 Arndt M, Juffmann T, Vedral V. Quantum physics meets biology. HFSP J 2009;3:386-400

123 Vattay G, Kauffman S, Niiranen S. Quantum biology on the edge of quantum chaos. PLoS One 2014;9:e89017-e89017

124 Bischof M, Del Giudice E. Communication and the emergence of collective behavior in living organisms: a quantum approach. Mol Biol Int 2013;2013:987549

125 Davies PC. Does quantum mechanics play a non-trivial role in life? Biosystems 2004;78:69-79 
126 Ho M-W. Illuminating water and life: Emilio Del Giudice. Electromagn Biol Med 2015;34:113-122

127 Kafatos MC, Chevalier G, Chopra D, Hubacher J, Kak S, Theise ND. Biofield science: current physics perspectives. Glob Adv Health Med 2015;4:25-34

128 Mansur HS. Quantum dots and nanocomposites. Wiley Interdiscip Rev Nanomed Nanobiotechnol 2010;2:113-129

129 Walach H, Tressoldi PE, Pederzoli L. Mental, behavioral, and physiological nonlocal correlations within the Generalized Quantum Theory framework. Axiomathes 2016;26:313-328

130 Wang Y, Chen L. Quantum dots, lighting up the research and development of nanomedicine. Nanomedicine (Lond) 2011; 7:385-402

131 Lambert N, Chen YN, Cheng YC, Li CM, Chen GY, Nori F. Quantum biology. Nat Phys 2013;9:10-18

132 Chen SF, Cölfen H, Antonietti M, Yu SH. Ethanol assisted synthesis of pure and stable amorphous calcium carbonate nanoparticles. Chem Commun (Camb) 2013;49:9564-9566

133 Yoo JW, Yun DS, Kim HJ. Influence of reaction parameters on size and shape of silica nanoparticles. J Nanosci Nanotechnol 2006; 6:3343-3346

134 Treuel L, Docter D, Maskos M, Stauber RH. Protein corona - from molecular adsorption to physiological complexity. Beilstein J Nanotechnol 2015;6:857-873

135 Hajipour MJ, Laurent S, Aghaie A, Rezaee F, Mahmoudi M. Personalized protein coronas: a "key" factor at the nanobiointerface. Biomater Sci 2014;2:1210-1221

136 Tavakol M, Montazeri A, Naghdabadi R, et al. Disease-related metabolites affect protein-nanoparticle interactions. Nanoscale 2018;10:7108-7115

137 Walkey CD, Chan WC. Understanding and controlling the interaction of nanomaterials with proteins in a physiological environment. Chem Soc Rev 2012;41:2780-2799

138 Walkey CD, Olsen JB, Song F, et al. Protein corona fingerprinting predicts the cellular interaction of gold and silver nanoparticles. ACS Nano 2014;8:2439-2455

139 Liu R, Jiang W, Walkey CD, Chan WC, Cohen Y. Prediction of nanoparticles-cell association based on corona proteins and physicochemical properties. Nanoscale 2015;7:9664-9675

140 Caracciolo G, Farokhzad OC, Mahmoudi M. Biological identity of nanoparticles in vivo: clinical implications of the protein corona. Trends Biotechnol 2017;35:257-264

141 Cai R, Chen C. The Crown and the Scepter: roles of the protein corona in nanomedicine. Adv Mater 2019;31:e1805740

142 Nierenberg D, Khaled AR, Flores O. Formation of a protein corona influences the biological identity of nanomaterials. Rep Pract Oncol Radiother 2018;23:300-308

143 Hajipour MJ, Raheb J, Akhavan O, et al. Personalized diseasespecific protein corona influences the therapeutic impact of graphene oxide. Nanoscale 2015;7:8978-8994

144 Sukul NC, Bala SK, Bhattacharyya B. Prolonged cataleptogenic effects of potentized homoeopathic drugs. Psychopharmacology (Berl) 1986;89:338-339

145 Iavicoli I, Calabrese EJ, Nascarella MA. Exposure to nanoparticles and hormesis. Dose Response 2010;8:501-517

146 Bell IR, Schwartz GE. Adaptive network nanomedicine: an integrated model for homeopathic medicine. Front Biosci (Schol Ed) 2013;5:685-708

147 Sun P, Zhang S-J, Maksim S, Yao Y-F, Liu H-M, Du J. Epigenetic Modification in Macrophages: a promising target for tumor and inflammation-associated disease therapy. Current Topics in Medicinal Chemistry 2019;19:1350-1362

148 Calabrese EJ, Giordano JJ, Kozumbo WJ, Leak RK, Bhatia TN. Hormesis mediates dose-sensitive shifts in macrophage activation patterns. Pharmacol Res 2018;137:236-249

149 de Oliveira CC, de Oliveira SM, Goes VM, Probst CM, Krieger MA, Buchi DF. Gene expression profiling of macrophages following mice treatment with an immunomodulator medication. J Cell Biochem 2008;104:1364-1377

150 Olioso D, Marzotto M, Bonafini C, Brizzi M, Bellavite P. Arnica montana effects on gene expression in a human macrophage cell line. Evaluation by quantitative Real-Time PCR. Homeopathy 2016;105:131-147

151 Teixeira MZ. Isopathic use of auto-sarcode of DNA as antimiasmatic homeopathic medicine and modulator of gene expression? Homeopathy 2019;108:139-148

152 Fleischer CC, Payne CK. Nanoparticle-cell interactions: molecular structure of the protein corona and cellular outcomes. Acc Chem Res 2014;47:2651-2659

153 Safdar A, Tarnopolsky MA. Exosomes as mediators of the systemic adaptations to endurance exercise. Cold Spring Harb Perspect Med 2018;8:8

154 Frühbeis C, Helmig S, Tug S, Simon P, Krämer-Albers EM. Physical exercise induces rapid release of small extracellular vesicles into the circulation. J Extracell Vesicles 2015;4:28239

$155 \mathrm{Mu}$ J, Zhuang $X$, Wang $Q$ et al. Interspecies communication between plant and mouse gut host cells through edible plant derived exosome-like nanoparticles. Mol Nutr Food Res 2014;58:1561-1573

156 Zhu M, Li Y, Shi J, Feng W, Nie G, Zhao Y. Exosomes as extrapulmonary signaling conveyors for nanoparticle-induced systemic immune activation. Small 2012;8:404-412

157 Tan A, De La Peña H, Seifalian AM. The application of exosomes as a nanoscale cancer vaccine. Int J Nanomedicine 2010;5:889-900

158 Gallo PM, Gallucci S. The dendritic cell response to classic, emerging, and homeostatic danger signals. Implications for autoimmunity. Front Immunol 2013;4:138

159 Schaefer L. Complexity of danger: the diverse nature of damageassociated molecular patterns. J Biol Chem 2014;289:35237-35245

160 Mazloomi E, Ilkhanizadeh B, Zare A, Shahabi S. Evaluation of the efficacy of isopathic immunotherapy in the treatment of allergic asthma in BALB/C mice. J Asthma 2019;3:1-10

161 Frenkel M, Mishra BM, Sen S, et al. Cytotoxic effects of ultradiluted remedies on breast cancer cells. Int J Oncol 2010; 36:395-403

162 Preethi K, Ellanghiyil S, Kuttan G, Kuttan R. Induction of apoptosis of tumor cells by some potentiated homeopathic drugs: implications on mechanism of action. Integr Cancer Ther 2012;11:172-182

163 Banerji P, Banerji P. The Banerji Protocols: A New Method of Treatment with Homeopathic Medicine. Kolkata, India: PBH Research Foundation; 2013

164 Hao S, Bai O, Li F, Yuan J, Laferte S, Xiang J. Mature dendritic cells pulsed with exosomes stimulate efficient cytotoxic T-lymphocyte responses and antitumour immunity. Immunology 2007; 120:90-102

165 Hosseini HM, Fooladi AA, Nourani MR, Ghanezadeh F. The role of exosomes in infectious diseases. Inflamm Allergy Drug Targets 2013;12:29-37

166 Reale M, Kamal MA, Patruno A, et al. Neuronal cellular responses to extremely low frequency electromagnetic field exposure: implications regarding oxidative stress and neurodegeneration. PLoS One 2014;9:e104973

167 Tokalov SV, Gutzeit HO. Weak electromagnetic fields $(50 \mathrm{~Hz})$ elicit a stress response in human cells. Environ Res 2004;94:145-151

168 Lunt HC, Barwood MJ, Corbett J, Tipton MJ. 'Cross-adaptation': habituation to short repeated cold-water immersions affects the response to acute hypoxia in humans. J Physiol 2010;588:36053613

169 Pilla A, Fitzsimmons R, Muehsam D, Wu J, Rohde C, Casper D. Electromagnetic fields as first messenger in biological signaling: application to calmodulin-dependent signaling in tissue repair. Biochim Biophys Acta 2011;1810:1236-1245

170 Bell IR, Schwartz GE, Frye J, Sarter B, Standish LJ. Extending the adaptive network nanomedicine model for homeopathic 
medicine: nanostructures as salient cell danger signals for adaptation. Nanoscience Technology 2015;2:1-22

171 Pincus D, Metten A. Nonlinear dynamics in biopsychosocial resilience. Nonlinear Dyn Psychol Life Sci 2010;14:353-380

172 Martel J, Wu CY, Peng HH, Young JD. Mineralo-organic nanoparticles in health and disease: an overview of recent findings. Nanomedicine (Lond) 2018. Doi: 10.2217/nnm-2018-0108

173 Peng CK, Buldyrev SV, Hausdorff JM, et al. Non-equilibrium dynamics as an indispensable characteristic of a healthy biological system. Integr Physiol Behav Sci 1994;29:283-293

174 Goldberger AL, Amaral LA, Hausdorff JM, Ivanov PCh, Peng CK, Stanley HE. Fractal dynamics in physiology: alterations with disease and aging. Proc Natl Acad Sci U S A 2002;99: 2466-2472

175 Klein SD, Würtenberger S, Wolf U, Baumgartner S, Tournier A. Physicochemical investigations of homeopathic preparations: a systematic review and bibliometric analysis-Part 1. J Altern Complement Med 2018;24:409-421

176 Milisav I, Poljsak B, Suput D. Adaptive response, evidence of cross-resistance and its potential clinical use. Int J Mol Sci 2012; 13:10771-10806

177 Kokornaczyk MO, Dinelli G, Marotti I, Benedettelli S, Nani D, Betti L. Self-organized crystallization patterns from evaporating droplets of common wheat grain leakages as a potential tool for quality analysis. ScientificWorldJournal 2011;11:1712-1725

178 Preparata G. A bridge from physics to biology. Riv Biol 2010; 103:289-298

179 Brizhik L, Foletti A. Nonlinear quantum phenomena and biophysical aspects of complexity related to health and disease. J Biol Regul Homeost Agents 2014;28:357-366

180 Foletti A, Brizhik L. Nonlinearity, coherence and complexity: biophysical aspects related to health and disease. Electromagn Biol Med 2017;36:315-324

181 Nguyen VH, Lee BJ. Protein corona: a new approach for nanomedicine design. Int J Nanomedicine 2017;12:3137-3151

182 Van Wijk R, Wiegant FA. Postconditioning hormesis and the similia principle. Front Biosci (Elite Ed) 2011;3:1128-1138

183 Wiegant FA, Prins HA, Van Wijk R. Postconditioning hormesis put in perspective: an overview of experimental and clinical studies. Dose Response 2011;9:209-224

184 Wiegant FA, Spieker N, van Wijk R. Stressor-specific enhancement of HSP induction by low doses of stressors in conditions of self- and cross-sensitization. Toxicology 1998;127:107-119

185 Chikramane PS, Suresh AK, Kane SG, Bellare JR. Metal nanoparticle induced hormetic activation: a novel mechanism of homeopathic medicines. Homeopathy 2017;106:135-144
186 Bigagli E, Luceri C, Bernardini S, Dei A, Filippini A, Dolara P. Exploring the effects of homeopathic Apis mellifica preparations on human gene expression profiles. Homeopathy 2014; 103:127-132

187 Dei A, Bernardini S. Hormetic effects of extremely diluted solutions on gene expression. Homeopathy 2015;104:116-122

188 Marzotto M, Olioso D, Brizzi M, Tononi P, Cristofoletti M, Bellavite P. Extreme sensitivity of gene expression in human SH-SY5Y neurocytes to ultra-low doses of Gelsemium sempervirens. BMC Complement Altern Med 2014;14:104

189 Csermely P, Korcsmáros T, Nussinov R. Intracellular and intercellular signaling networks in cancer initiation, development and precision anti-cancer therapy: RAS acts as contextual signaling hub. Semin Cell Dev Biol 2016;58:55-59

190 Khuda-Bukhsh AR, Bhattacharyya SS, Paul S, Dutta S, Boujedaini $\mathrm{N}$, Belon P. Modulation of signal proteins: a plausible mechanism to explain how a potentized drug Secale Cor 30C diluted beyond Avogadro's limit combats skin papilloma in mice. Evid Based Complement Alternat Med 2011;2011:286320

191 Bell IR, Sarter B, Koithan M, et al. Integrative nanomedicine: treating cancer with nanoscale natural products. Glob Adv Health Med 2014;3:36-53

192 Saha S, Hossain DM, Mukherjee S, et al. Calcarea carbonica induces apoptosis in cancer cells in p53-dependent manner via an immuno-modulatory circuit. BMC Complement Altern Med 2013;13:230

193 Saha S, Bhattacharjee P, Guha D, et al. Sulphur alters NFrB-p300 cross-talk in favour of p53-p300 to induce apoptosis in nonsmall cell lung carcinoma. Int J Oncol 2015;47:573-582

194 Antelman SM, Caggiula AR. Oscillation follows drug sensitization: implications. Crit Rev Neurobiol 1996;10:101-117

195 Antelman SM, Levine J, Gershon S. Time-dependent sensitization: the odyssey of a scientific heresy from the laboratory to the door of the clinic. Mol Psychiatry 2000;5:350-356

196 Bertani S, Lussignoli S, Andrioli G, Bellavite P, Conforti A. Dual effects of a homeopathic mineral complex on carrageenan-induced oedema in rats. Br Homeopath J 1999;88:101-105

197 Bell IR, Howerter A, Jackson N, Aickin M, Bootzin RR, Brooks AJ. Nonlinear dynamical systems effects of homeopathic remedies on multiscale entropy and correlation dimension of slow wave sleep EEG in young adults with histories of coffee-induced insomnia. Homeopathy 2012;101:182-192

198 Belon P, Elia V, Elia L, Montanino M, Napoli E, Niccolli M. Conductometric and calorimetric studies of the serially diluted and agitated solutions. J Therm Anal Calorim 2008; 93:459-469 